\title{
Fish density, but not environmental enrichment, affects the size of cerebellum in the brain of juvenile hatchery-reared Atlantic salmon
}

\author{
Joacim Näslund $(\mathbb{D}$ • Malin Rosengren • Jörgen I. Johnsson
}

Received: 15 July 2018 / Accepted: 3 March 2019/Published online: 15 March 2019

(C) The Author(s) 2019

\begin{abstract}
This paper describes a study on the environmentally dependent brain size plasticity in hatcheryreared Atlantic salmon Salmo salar L. Using a factorial experimental design, we tested whether tank fish density, local hatchery standard $\left(150 \mathrm{fish} \cdot \mathrm{m}^{-2}\right)$ vs. reduced (50 fish $\cdot \mathrm{m}^{-2}$ ) and structural enrichment, a bundle of submerged plastic stripes, had effects on the size of the cerebellar region of the brain. Fish reared at reduced density had smaller cerebella, while structural enrichment had no detectable effects. The density effect on cerebellum, which is involved in locomotion and cognition, confirms previous results from hatchery-reared Atlantic salmon. The lack of detectable positive effects of enrichment, which contrasts some previous studies, provide further evidence for a complex relationship between environmental complexity and brain growth.
\end{abstract}

Jörgen I. Johnsson died before publication of this work was completed.

Electronic supplementary material The online version of this article (https://doi.org/10.1007/s10641-019-00864-9) contains supplementary material, which is available to authorized users.

J. Näslund $(\bowtie) \cdot$ M. Rosengren $\cdot$ J. I. Johnsson

Department of Biological and Environmental Sciences, University of Gothenburg, Gothenburg, Sweden

e-mail: joacim.naslund@gmail.com

Present Address:

J. Näslund

Department of Zoology, Stockholm University, Stockholm,

Sweden
Keywords Salmonids · Cerebellum size ·

Environmental enrichment · Tank density · Hatchery

environment

\section{Introduction}

Stocking of juvenile hatchery-reared fish is a common, but also controversial, practice (e.g. Lorenzen 2014; Stewart et al. 2015). Typically, fish are reared at high densities in barren environments, provided food in excess, and never encounter predatory threats, which may lead to behavioural deficits in a natural environment (Brown and Day 2002; Johnsson et al. 2014). Critique has been raised against the fact that many stocking programs are focused on the number of stocked fish, rather than the number of surviving fish (CHSRG 2012; Johnsson et al. 2014). Furthermore, analyses of long-term data from a salmon stocking programme have suggested no benefits to the stock in general (Glover et al. 2018). In salmonid fish, survival of stocked fish is commonly less than half of that of wild conspecifics with the same genetic origin (Jonsson and Jonsson 2011), with most of the mortality occurring very soon after release (e.g. Saloniemi et al. 2004; Aarestrup et al. 2014; Melnychuk et al. 2014). However, in some cases the post-release performance of hatchery-reared fish is similar to that of wild conspecifics, which suggests that hatchery rearing practices can be adapted to produce wellperforming stock fish (Araki and Schmid 2010). Hatchery rearing has been known to produce fish with different characteristics than wild fish for at least a century, and this is a likely cause of the poor wild performance (Robertson 
1919; Schuck 1948; Blaxter 1970; Johnsson et al. 2014). Consequently, recent research has investigated whether more wild-like fish can be produced through alterations of the artificial hatchery environment (Brännäs and Johnsson 2008; Johnsson et al. 2014). The early rearing environment can have substantial effects on the future performance of fish (Browman 1989; Jonsson and Jonsson 2014). This is particularly apparent in artificially reared fish, where changes of the traditional hatchery environments have been shown to affect the performance of the hatchery fish in the wild, including tank-density reductions and structural enrichment (Johnsson et al. 2014; Näslund and Johnsson 2016).

Traits shown to differ between hatchery and wild fish, and that can have important implications for success in the wild, include the relative size of the brain or brain subregions (Marchetti and Nevitt 2003; Kihslinger and Nevitt 2006; Mayer et al. 2011). As several studies have shown that the fish brain is affected by environmental conditions (reviewed in Ebbesson and Braithwaite 2012), this was the focus of the present study. Structural enrichment (defined here as a deliberate increase in environmental complexity with the aim to provide a beneficial environment for the reared animals; Näslund and Johnsson 2016) has been shown to induce positive effects on brain cell proliferation in the forebrain of several species of captive animals (von Krogh et al. 2010; Clemenson et al. 2015), including Atlantic salmon Salmo salar (Salvanes et al. 2013). Furthermore, structural enrichment has been shown to have positive effects on the relative brain size in Atlantic salmon fry (Näslund et al. 2012), as well as positive effects on the size of cerebellum in chinook salmon Oncorhynchus tshawytscha (Kihslinger and Nevitt 2006). One interpretation of these studies is that the enriched environment appears to stimulate brain growth, which may be linked to increased cognitive ability (Kotrschal et al. 2013; Salvanes et al. 2013). However, at least one study found that structural enrichment decreased forebrain cell proliferation (Lema et al. 2005), another study showed no positive effects of enrichment on relative forebrain size (Kihslinger et al. 2006), and a third found a general negative effect of semi-natural rearing as compared to tank-rearing (Kotrschal et al. 2012). Thus, the effects may depend on the type of enrichment used, species under investigation, or on the life stage where the fish are exposed to the enrichment. Some effects have also been speculated to depend on differential allometric growth patterns in different environments (e.g. the growth of the body relative to the head) (Näslund et al. 2012; Brignon et al. 2018).
In comparison with structural enrichment, group size is less investigated with respect to brain growth, but may still be an important environmental factor (Gonda et al. 2009, 2013; Johnsson et al. 2014; Fischer et al. 2015). A recent study on Atlantic salmon reared at either high or low density showed that the cerebellum and telencephalon, both being brain subregions involved in cognitive ability (Ebbesson and Braithwaite 2012), were found to be larger on average in individuals reared at high density in a Danish salmon hatchery (Näslund et al. 2017). High-density fish from the same experiment did, however, have lower survival when released into the wild, speaking against a strong benefit of the environmentally induced effects on the brain (Larsen et al. 2016).

In the present study, we investigated the size of cerebellum in hatchery-reared Atlantic salmon reared at high (local hatchery standard) or low (1/3 of local hatchery standard) density, in presence or absence of structural enrichment (in a factorial design). The cerebellar region of the brain is involved in motor control as well as sensorymotor control and spatial learning (Rodríguez et al. 2005; Yopak et al. 2017), which makes it a potentially important structure for salmonids, which resides and actively swim in both complex fast-flowing rivers and in open oceanic environments. Based on previous results in the published literature, we hypothesized that structural enrichment and high density would stimulate cerebellar growth (Kihslinger and Nevitt 2006; Fischer et al. 2015; Näslund et al. 2017). The overall aim of the project (SMOLTPRO; http://smoltpro.gu.se/) of which the present study was a part, was to assess how rearing conditions affect performance of juvenile Atlantic salmon stocked in rivers as pre-smolts, with an aim to produce smolts as close to the wild phenotype as possible. As a baseline assumption, a larger cerebellum was considered to be indicative of a more wild-like phenotype, following previously published results showing negative effects of hatchery rearing on brain-size in general and cerebellum size in particular (Marchetti and Nevitt 2003; Kihslinger and Nevitt 2006; Mayer et al. 2011; but see Brignon et al. 2018).

\section{Materials and methods}

Animals and rearing conditions

The fish in this study were a subsample of the fish included in the study by Rosengren et al. (2017). This experimental population was derived from 15 male and 30 female adult 
wild Atlantic salmon from the River Imsa, Norway $\left(58^{\circ} 54^{\prime} \mathrm{N}, 5^{\circ} 57^{\prime} \mathrm{E}\right)$, bred in a 1:2 crossing matrix (1 male to 2 females) with eggs being artificially fertilized in autumn 2011 and reared at Ims Research Station (Norwegian Institute for Nature Research). On 8 October 2012, 2400 fish were transferred from barren hatchery tanks to treatment tanks (bottom area: $2 \mathrm{~m}^{2}$, water depth: approx. $30 \mathrm{~cm}$ ), where they were maintained until they were sampled in mid-May 2013. Treatments were replicated in three tanks each and consisted of a $2 \times 2$ factorial setup, with two densities of fish [high (H) or low (L)] and two levels of structural enrichment [enriched (E) or simple (S)]. High density corresponded to the typical local hatchery densities (150 individuals $\cdot \mathrm{m}^{-2}$; average mass density at sampling: $14.4 \mathrm{~kg} \cdot \mathrm{m}^{-3}$ ) and the low density corresponded to a third of the high density ( 50 individuals $\cdot \mathrm{m}^{-2}$; average mass density at sampling: $4.8 \mathrm{~kg} \cdot \mathrm{m}^{-3}$ ). Each of the enriched tanks had a bundle of submerged black polyethylene stripes (100 stripes, $50 \mathrm{~cm}$ long, $7 \mathrm{~cm}$ broad), which covered an area of approximately $1 \mathrm{~m}^{2}$. Simple tanks consisted of normal barren hatchery tanks. Water from a nearby lake was supplied continuously to all tanks and food pellets were supplied in excess from automatic food dispensers (Ewos No. 505, Ewos AS, Skårer, Norway) throughout the experiment. Further details and photographs of the experimental tanks can be found in Rosengren et al. (2017).

\section{Sampling}

The fish analysed in this study were sampled on 13-14 May 2013, as part of a cortisol and intestinal barrier function sampling protocol (Rosengren et al. 2017). All sampled fish had initiated smoltification at the sampling occasion, but silvering index differed among individuals (although, not among treatments; Rosengren et al. 2017). Photographs were taken of each fish immediately after euthanization (by overdose of metomidate, $6 \mathrm{mg} \cdot \mathrm{L}^{-1}$; Aquacalm, Syndel, Nanaimo, Canada) along with a millimetre scale, from which fork length was measured using the software ImageJ 1.45r (Schneider et al. 2012). Thereafter, the fish were decapitated, and the heads fixed in $4 \%$ phosphate-buffered formaldehyde, in which they were individually stored at $4{ }^{\circ} \mathrm{C}$ until dissection.

Brain dissection

The dissections were conducted in autumn 2015. Preserved heads were dorsoventrally bisected along the midsagittal plane using a scalpel, whereafter the brains were dissected out of each half of the heads. The cerebellum was separated from the rest of the brain while still inside the cranium, following the dissection protocol in Näslund et al. (2017) (see Fig. S1 in the electronic supplement). The cerebella were dried at $70{ }^{\circ} \mathrm{C}$ for $35 \mathrm{~h}$ and thereafter weighed to the nearest $0.01 \mathrm{mg}$ (Precisa XR 205SM-DR; Precisa Gravimetrics AG, Dietikon, Switzerland). The original aim was to also investigate telencephalon and total brain size, but the telencephalon measurements indicated excessively inflated size variation, as compared to previous studies, with dry mass being noted as up to twice as large as expected based on the size of the fish (Näslund et al. 2017). This was judged to be highly likely to represent procedural mistakes when collecting the mass data (a visualization of these data in the electronic supplement: Fig. S2). The cerebellar measurements did not show any indications of measurement errors, and fitted well within the expected range of dry mass, as compared to Näslund et al. (2017) (electronic supplement: Fig. S3). Hence, the cerebellar measurements were retained for analyses, while telencephalic and whole brain data were discarded. The person $(\mathrm{JN})$ dissecting and measuring the brains was blind to treatment when performing these tasks.

\section{Analyses}

Cerebellar size is strongly correlated with body size in the study species, and the aim was to correct the measurements for fork length in a robust way. Based on previous analyses of salmon brain dry mass in relation to social environment (Näslund et al. 2017), the effect sizes are expected to be relatively small. Given the relatively small sample size and narrow size-span, which increases variance and outlier sensitivity of slope estimations in the linear modelling, we therefore chose to standardize data based on slope estimates of the body length vs. cerebellar dry mass relationship from a data set where we combined the present data with data from Näslund et al. (2017) (Fig. S3 in the electronic supplement illustrates the improved fit of this method, as compared to the slope estimates based on the data from the current study only). This method gave us relative cerebellum size estimates without adding body length as a covariate in the statistical models; however, it also leads to an implicit assumption of no interactive effects between treatment and body size. We calculated residuals by fitting the cerebellum size data around the estimated slopes by minimizing sums of squares for the whole data set, and 
used these residuals in an ANOVA, including the factors Density [two levels: high (H) and low (L)] and Enrichment [two levels: present (E) and absent (S)]. Illustrations of data are presented as body size vs. cerebellum dry mass scatterplots, including the slope used for calculations of residuals (Fig. 1). The interaction between the two environmental factors was initially investigated, but removed from the model if no potential effect could be detected $(p>0.1)$, which was indeed the case $(p>0.28)$. Tank effects were not included, since the sample size from each tank was regarded too low (maximally 4 individuals per tank) to produce reliable tank-effect estimates; thus, we acknowledge that potential tank effects are unknown in our study (data for each tank is visualized in Fig. S4 in the electronic supplement). Normality and homoscedasticity were judged to be acceptable based on Q-Q plots and box-plots, respectively.

To obtain an indication of whether the overall brain size was affected by the treatments, we analysed the dry mass of the brain without including telencephalon or cerebellum, following the same procedure as for cerebellum.

Analyses were conducted in R (R Core Team 2017) using linear modelling from the 'stats' package with type III sums-of-squares for hypothesis testing calculated with the 'car' package. Results were regarded significant when $p<0.05$. Parameter estimates $(\beta)$ are presented for the treatments Density $=$ L (i.e. how L differ

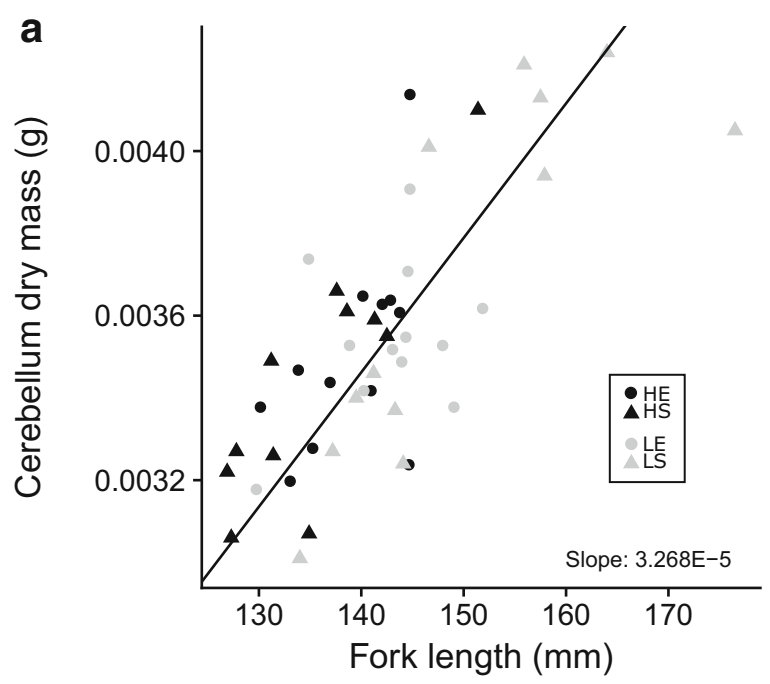

Fig. 1 a Dry mass of cerebellum, along with the estimated body size relationship used to calculate residuals for analysis (black line). HE: high density + enrichment present; HS: high density + enrichment absent; LE: low density + enrichment present; LS: low density + enrichment absent. b Box-and-whisker plots illustrating the data distribution for calculated cerebellum dry mass residuals from $\mathrm{H}$ ) and Enrichment = S (i.e. how S differ from E), along with standard errors of the estimates.

Although smoltification status (i.e. silvering index) did not differ significantly among sampled fish in the treatment groups (see results in Rosengren et al. 2017), we nevertheless used a correlation analysis to check for indications of smoltification status affecting sizecorrected cerebellum size, since cerebellum size is increased during smoltification (Näslund et al. 2017).

Damage of the cerebellum during dissection reduced the sample size in the HS treatment leaving $N=47$ (HE: 12; HS: 11; LE: 12; LS: 12).

\section{Results}

A significant effect was detected for Density, with fish from the high-density treatment having higher cerebellar dry mass $\left(F_{1,44}=5.53 ; p=0.023 ; \beta(\mathrm{L}) \pm \mathrm{SE}=-0.00015\right.$ $\pm 0.000064)$ (Fig. 1). No effect of Enrichment could be detected $\left(F_{1,44}=0.043 ; p=0.84 ; \beta(\mathrm{S}) \pm \mathrm{SE}=-0.000013\right.$ $\pm 0.000064)$. No indication of cerebellum size being associated with smolt status (silvering index) was found (Pearson $r=0.042, p=0.78$ ). Overall, the clear majority ( 40 out of 48) of all fish investigated showed complete silvering, indicative of being ready for seaward migration (see results in Rosengren et al. 2017).

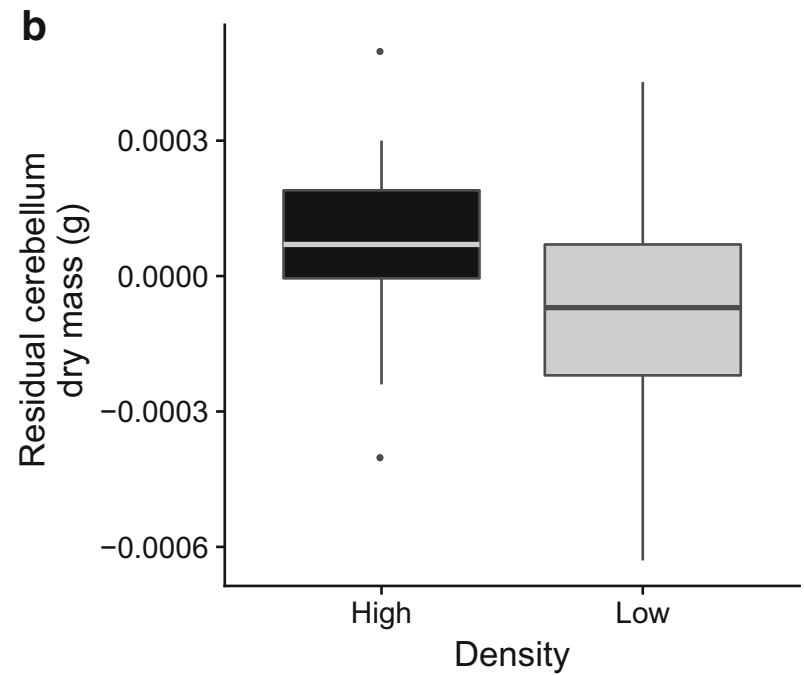

in relation to the Density treatment. The box-hinges delineate the interquartile range (IQR), with the median shown as a horizontal bar across the box. Whiskers delineate minimum and maximum values, excluding outliers located $>1.5$ IQR from the box hinges (shown as individual points) 
No effects of any of the treatments, or their interaction, were found in the analysis investigating the dry mass of the brain tissue excluding cerebellum and telencephalon (all $p>0.14$ ).

\section{Discussion}

In this study, we found that the cerebellum dry mass was higher in the high-density treatment, while no effects of structural enrichment were detected.

The finding that the cerebellar subregion is positively influenced by tank stocking density is in line with another recent study on Atlantic salmon parr and pre-smolt (size range at sampling: 70-165 mm) from a Danish hatchery (Näslund et al. 2017). In the previous study, both densities were higher than any of the treatments in the present study (4 $\mathrm{m}^{2}$ tanks, depth: $35 \mathrm{~cm}$; high density: 1500 individuals . $\mathrm{m}^{-2}$; low density: 500 individuals $\cdot \mathrm{m}^{-2}$ ), suggesting that the fish are further affected with densities above the ones investigated in the present study.

Given that the cerebellum is involved in both motor function and spatial cognition (Rodríguez et al. 2005; Yopak et al. 2017), it is possible that this brain region is stimulated in an environment where good manoeuvrability is required, e.g. an environment with a high density of conspecifics. Comparative interspecific studies show that cerebellum is often larger in species showing a more active swimming behaviour, with higher manoeuvrability and agility (Yopak et al. 2017). A larger cerebellum could thereby be indicative of a higher motor performance and navigation ability, traits that likely would be beneficial for stock fish after being released into the wild. However, the high-density groups did not perform better, in terms of migration performance in the wild (Larsen et al. 2016; Rosengren et al. 2017), in either of these two studies. Potentially, other effects stemming from the density treatment may have masked any effects of a larger cerebellum. In Larsen et al. (2016), fish from high density had a substantially increased mortality rate during their post-release downstream smolt migration in a natural river. In Rosengren et al. (2017), i.e. the same project as the present study, fish reared in high density were found to migrate either less successfully (if also being reared with enrichment) or equally well (if being reared without enrichment), as compared to fish reared in low density. Hence, it appears that smolt quality should not be judged based on single characters such as the size of the brain or its subregions.
The volume of the cerebellum may have little influence of post-release performance overall, considering that traits like body-size and muscle-mass may be more important for survival and swimming performance. A recent study by Brignon et al. (2018) found that the cerebellum of wild one-year-old bull trout Salvelinus confluentus was smaller than that of hatchery-reared conspecifics, putting into question whether a larger cerebellum is indicative of a wild-like phenotype. Furthermore, Näslund et al. (2012), found that fish stocked into a river ended up with larger body and smaller relative brain size, indicating that brain growth may be less important than body growth in natural systems.

The lack of effects of structural enrichment on the cerebellar region is interesting, since several previous studies show that such enrichment can be associated with a relative enlargement of the cerebellum, or the brain in general (Kihslinger and Nevitt 2006; Näslund et al. 2012). One explanation for the differences could be that the growth of the salmon brain, and its subregions, is not directly stimulated by a more complex environment per se. Instead, enrichment may influence energy intake and thereby the available energy to distribute to neural growth (discussed in Johnsson et al. 2014; Näslund and Johnsson 2016). Some of the studies showing positive effects on brain growth from structural enrichment in salmonids are made on the yolk-sac fry stage, just after hatching (Kihslinger and Nevitt 2006; Näslund et al. 2012). During this stage, enrichment will provide support for maintaining a stable body position and thereby reducing activity and energy expenditure (Marr 1963; Leon 1975; Hansen and Torrissen 1985), leaving more energy from the yolk available for neural growth. It may also be that different types of enrichment differ in their stimulatory effects on the brain growth patterns.

A couple of studies indicate that neurogenesis is faster in structurally enriched environments, but these studies did not consider brain size variables per se (von Krogh et al. 2010; Salvanes et al. 2013). While there are studies finding positive effects of structural enrichment (at least conditionally so) on brain size in fish past the fry stage (threespined stickleback Gasterosteus aculeatus: Herczeg et al. 2015; zebrafish Danio rerio: DePasquale et al. 2016), other studies suggest that enrichment has no or negative effect on the brain size (chinook salmon: Lema et al. 2005; Kihslinger et al. 2006; 
guppy Poecilia reticulata: Burns et al. 2009; coho salmon Oncorhynchus kisutch: Kotrschal et al. 2012; Eastern mosquitofish Gambusia holbrooki: Turschwell and White 2016; three-spined stickleback: Toli et al. 2017; bull trout: Brignon et al. 2018). The results of our study provide further evidence that structural enrichment may not always affect brain or brain subregion growth.

From the point of view of the present study, it is interesting to note that Kihslinger and Nevitt (2006) reports increased size of the cerebellar volume in steelhead yolk-sac fry reared in a structurally enriched environment, a similar effect as seen from higher density in the present study. Kihslinger and Nevitt (2006) used stones as enrichment and given the strongly gravitaxic behaviour of salmonid yolksac fry (Roth and Geiger 1963), the fish would likely aggregate at the bottom among the stones, which effectively would increase the fish (and object) density in the remaining available space. Hence, it might be possible that the effects observed were due to density rather than enrichment. However, differences in effects of enrichment on the brain could also be due to the fact that a different life-stage (yolk-sac fry), and a different type of enrichment structure (stones), were investigated in Kihslinger and Nevitt (2006).

The size of the cerebellar size was corrected for body size to provide a relative size-estimate. Given that the telencephalon-measures were judged to be erroneous, we could not calculate the relative size as compared to the whole brain as in e.g. Näslund et al. (2017). However, in the latter study, the patterns of relative cerebellar size were similar when correcting for either body size or total brain size. No indications of treatment effects on the rest of the brain dry mass (i.e. excluding telencephalon and cerebellum) were found, suggesting that it was indeed the cerebellar region that was affected in this study.

Further investigations into effects of density vs. environmental complexity on fish brain development are warranted to tease out relative effects of fish density and enrichment over the ontogeny in salmonids. Furthermore, direct investigations of whether or not brain, or brain subregion, volumes have any effects on the performance of hatchery reared fish in the wild are needed to evaluate the importance of investigating brain size from a hatchery-rearing perspective.
Acknowledgements This study was conducted as part of the strategic project SMOLTPRO, financed by the Swedish Research Council FORMAS. Additional funding was provided from Adlerbertska forskningsstiftelsen to JN and MR. The staff at Ims Research Station are thanked for kindly providing hospitality, expertise, and maintenance of the fish. Researchers involved in the SMOLTPRO project, in particular Eli Kvingedal and Snuttan Sundell, are thanked for considerable input on the experimental design of the main study from which the samples were collected. Experiments were conducted according to national regulation under license No. 051 granted by the Norwegian Animal Research Authority to the NINA Research Station, Ims.

Open Access This article is distributed under the terms of the Creative Commons Attribution 4.0 International License (http:// creativecommons.org/licenses/by/4.0/), which permits unrestricted use, distribution, and reproduction in any medium, provided you give appropriate credit to the original author(s) and the source, provide a link to the Creative Commons license, and indicate if changes were made.

\section{References}

Aarestrup K, Baktoft H, Koed A, del Villar-Guerra D, Thorstad EB (2014) Comparison of the riverine and early marine migration behaviour and survival of wild and hatcheryreared sea trout Salmo trutta smolts. Mar Ecol Prog Ser 496:197-206. https://doi.org/10.3354/meps 10614

Araki H, Schmid C (2010) Is hatchery stocking a help or harm? Evidence, limitations and future directions in ecological and genetic surveys. Aquaculture 308:S2-S11. https://doi. org/10.1016/j.aquaculture.2010.05.036

Blaxter JHS (1970) Sensory deprivation and sensory input in rearing experiments. Helgol Wiss Meeresunters 20:642654. https://doi.org/10.1007/BF01609937

Brännäs E, Johnsson JI (2008) Behaviour and welfare in farmed fish. In: Magnhagen C, Braithwaite VA, Forsgren E, Kapoor BG (eds) Fish Behaviour, CRC Press, Boca Raton, pp 593628

Brignon WR, Pike MM, Ebbesson LOE, Schaller HA, Peterson JT, Schreck CB (2018) Rearing environment influences boldness and prey acquisition behavior, and brain and lens development of bull trout. Environ Biol Fish 101:383-401. https://doi.org/10.1007/s10641-017-0705-z

Browman HI (1989) Embryology, ethology and ecology of ontogenetic critical periods in fish. Brain Behav Evol 34:5-12. https://doi.org/10.1159/000116486

Brown C, Day RL (2002) The future of stock enhancements: lessons for hatchery practice from conservation biology. Fish Fish 3:79-94. https://doi.org/10.1046/j.14672979.2002.00077.x

Burns JG, Saravanan A, Rodd FH (2009) Rearing environment affects the brain size of guppies: lab-reared guppies have smaller brains than wild-caught guppies. Ethology 115: 122-133. https://doi.org/10.1111/j.1439-0310.2008.01585.x 
CHSRG (California Hatchery Scientific Review Group) (2012) California hatchery review report. US Fish and Wildlife Service and Pacific States Marine Fisheries Commission

Clemenson GD, Deng W, Gage FH (2015) Environmental enrichment and neurogenesis: from mice to humans. Curr Opin Behav Sci 4:56-62. https://doi.org/10.1016/j. cobeha.2015.02.005

DePasquale C, Neuberger T, Hirrlinger AM, Braithwaite VA (2016) The influence of complex and threatening environments in early life on brain size and behaviour. Proc R Soc B 283:20152564. https://doi.org/10.1098/rspb.2015.2564

Ebbesson LOE, Braithwaite VA (2012) Environmental effects on fish neural plasticity. J Fish Biol 81:2151-2174. https://doi. org/10.1111/j.1095-8649.2012.03486.x

Fischer S, Besset-Nettelbeck M, Kotrschal A, Taborsky B (2015) Rearing-group size determines social competence and brain structure in a cooperatively breeding cichlid. Am Nat 186: 123-140. https://doi.org/10.1086/681636

Glover RS, Fryer RJ, Soulsby C, Bacon PJ, Malcolm IA (2018) Incorporating estimates of capture probability and river network covariance in novel habitat - abundance models: assessing the effecs of conservation stocking on catchmentscale production of juvenile Atlantic salmon (Salmo salar) from a long-term dataset. Ecol Indic 93:302-315. https://doi. org/10.1016/j.ecolind.2018.05.013

Gonda A, Herczeg G, Merilä J (2009) Habitat-dependent and -independent plastic responses to social environment in the nine-spined stickleback (Pungitius pungitius) brain. Proc R Soc B 267:2085-2092. https://doi.org/10.1098/rspb.2009.0026

Gonda A, Herczeg G, Merilä J (2013) Evolutionary ecology of intraspecific brain size variation: a review. Ecol Evol 3:27512764. https://doi.org/10.1002/ece3.627

Hansen T, Torrissen KR (1985) Artificial hatching substrate and different times of transfer to first feeding: effects on growth and protease activities of the Atlantic salmon (Salmo salar). Aquaculture 48:177-188. https://doi. org/10.1016/0044-8486(85)90103-6

Herczeg G, Gonda A, Balázs G, Noreikiene K, Merilä J (2015) Experimental evidence for sex-specific plasticity in adult brain. Front Zool 12:38. https://doi.org/10.1186/s12983-015-0130-0

Johnsson JI, Brockmark S, Näslund J (2014) Environmental effects on behavioural development: consequences for fitness of captive-reared fishes in the wild. J Fish Biol 85:19461971. https://doi.org/10.1111/jfb. 12547

Jonsson B, Jonsson N (2011) Ecology of Atlantic salmon and brown trout. Habitat as a template for life histories. Springer Science+Business Media, Inc., Heidelberg

Jonsson B, Jonsson N (2014) Early environment influences later performance in fishes. J Fish Biol 85:151-188. https://doi. org/10.1111/jfb.12432

Kihslinger RL, Nevitt GA (2006) Early rearing environment impacts cerebellar growth in juvenile salmon. J Exp Biol 209: 504-509. https://doi.org/10.1242/jeb.02019

Kihslinger RL, Lema SC, Nevitt GA (2006) Environmental rearing conditions produce forebrain differences in wild Chinook salmon Oncorhynchus tshawytscha. Comp Biochem Physiol A Mol Integr Physiol 145:145-151. https://doi.org/10.1016/j. cbpa.2006.06.041

Kotrschal A, Sundström LF, Brelin D, Devlin RH, Kolm N (2012) Inside the heads of David and Goliath: environmental effects on brain morphology among wild and growth-enhanced coho salmon Oncorhynchus kisutch. J Fish Biol 81:987-1002. https://doi.org/10.1111/j.1095-8649.2012.03348.x

Kotrschal A, Rogell B, Bundsen A, Svensson B, Zajitschek S, Brännström I, Immler S, Maklakov AA, Kolm N (2013) Artificial selection on relative brain size in the guppy reveals costs and benefits of evolving a larger brain. Curr Biol 23: 168-171. https://doi.org/10.1016/j.cub.2012.11.058

Larsen MH, Johnsson JI, Näslund J, Thomassen ST, Aarestrup K (2016) Reduced rearing density increases post-release migration success of Atlantic salmon (Salmo salar) smolts. Can J Fish Aquat Sci 73:804810. https://doi.org/10.1139/cjfas-2014-0563

Lema SC, Hodges MJ, Marchetti MP, Nevitt GA (2005) Proliferation zones in the salmon telencephalon and evidence for environmental influence on proliferation rate. Comp Biochem Physiol A Mol Integr Physiol 141:327-335. https://doi.org/10.1016/j.cbpb.2005.06.003

Leon KA (1975) Improved growth and survival of juvenile Atlantic salmon (Salmo salar) hatched in drums packed with a labyrinthine plastic substrate. Prog Fish Cult 37:158-163. https://doi.org/10.1577/1548-8659(1975)37

Lorenzen K (2014) Understanding and managing enhancements: why fisheries scientists should care. J Fish Biol 85:18071829. https://doi.org/10.1111/jfb. 12573

Marchetti MP, Nevitt GA (2003) Effects of hatchery rearing practises on brain structures of rainbow trout. Environ Biol Fish 66:9-14. https://doi.org/10.1023/A:1023269221678

Marr DHA (1963) The influence of surface contour on the behaviour of trout alevins S. trutta L. Anim Behav 11:412. https://doi.org/10.1016/S0003-3472(63)80148-7

Mayer I, Meager J, Sjkæraasen JE, Rodewald P, Sverdrup G, Fernö A (2011) Domestication causes rapid changes in heart and brain morphology in Atlantic cod (Gadus morhua). Environ Biol Fish 92:181-186. https://doi.org/10.1007 /s10641-011-9831-1

Melnychuk MC, Korman J, Hausch S, Welch DW, McCubbing DJF, Walters CJ (2014) Marine survival difference between wild and hatchery-reared steelhead trout determined during early downstream migration. Can J Fish Aquat Sci 71:831846. https://doi.org/10.1139/cjfas-2013-0165

Näslund J, Johnsson JI (2016) Environmental enrichment for fish in captive environments: effects of physical structures and substrates. Fish Fish 17:1-30. https://doi. org/10.1111/faf. 12088

Näslund J, Aarestrup K, Thomassen ST, Johnsson JI (2012) Early enrichment effects on brain development in hatchery-reared Atlantic salmon (Salmo salar): no evidence for a critical period. Can J Fish Aquat Sci 69:1481-1490. https://doi. org/10.1139/F2012-074

Näslund J, Larsen MH, Thomassen ST, Aarestrup K, Johnsson JI (2017) Environment-dependent plasticity and ontogenetic changes in the brain of hatchery-reared Atlantic salmon. J Zool 301:75-82. https://doi.org/10.1111/jzo.12392

R Core Team (2017) R: A language and environment for statistical computing. R Foundation for Statistical Computing, Vienna. https://www.R-project.org/

Robertson A (1919) Hatching fry in gravel. Trans Am Fish Soc 48:146-156. https://doi.org/10.1577/15488659(1918)48[146:HFIG]2.0.CO;2 
Rodríguez F, Durán E, Gómez A, Ocaña FM, Álvarez E, JiménezMoya F, Broglio C, Salas C (2005) Cognitive and emotional functions of the teleost fish cerebellum. Brain Res Bull 66: 365-370. https://doi.org/10.1016/j.brainresbull.2004.11.026

Rosengren M, Kvingedal E, Näslund J, Johnsson JI, Sundell K (2017) Born to be wild: effects of rearing density and environmental enrichment on stress, welfare, and smolt migration in hatchery-reared Atlantic salmon. Can J Fish Aquat Sci 74: 396-405. https://doi.org/10.1139/cjfas-2015-0515

Roth H, Geiger W (1963) Experimentelle Untersuchungen über das Verhalten der Bachforellenbrut in der Laichgrube. Schweiz Z Hydrol 25:202-218. https://doi.org/10.1007/BF02505196

Saloniemi I, Jokikokko E, Kallio-Nyberg I, Pasanen P (2004) Survival of reared and wild Atlantic salmon smolts: size matters more in bad years. ICES J Mar Sci 61:782-787. https://doi.org/10.1016/j.icesjms.2004.03.032

Salvanes AGV, Moberg O, Ebbesson LOE, Nilsen TO, Jensen KH, Braithwaite VA (2013) Environmental enrichment promotes neural plasticity and cognitive ability in fish. Proc R Soc B 280:20131331. https://doi.org/10.1098/rspb.2013.1331

Schneider CA, Rasband WS, Eliceiri KW (2012) NIH image to ImageJ: 25 years of image analysis. Nat Methods 9:671-675. https://doi.org/10.1038/nmeth.2089

Schuck HA (1948) Survival of hatchery trout in streams and possible methods of improving the quality of hatchery trout. Prog Fish Cult 10:3-14. https://doi.org/10.1577/15488640(1948)10[3:SOHTIS]2.0.CO;2
Stewart DC, McKelvey S, Armstrong JD (2015) Ranching to the rod: an evaluation of adult returns from hatchery-reared Atlantic salmon smolts released in Scottish rivers. Scott Mar Freshw Sci 6:1-13. https://doi.org/10.7489/1610-1

Toli EA, Noreikiene K, DeFaveri J, Merilä J (2017) Environmental enrichment, sexual dimorphism, and brain size in sticklebacks. Ecol Evol 7:1691-1698. https://doi. org/10.1002/ece3.2717

Turschwell MP, White CR (2016) The effects of laboratory housing and spatial enrichment on brain size and metabolic rate in the eastern mosquitofish, Gambusia holbrooki. Biol Open 5: 205-210. https://doi.org/10.1242/bio.015024

von Krogh K, Sørensen C, Nilsson GE, Øverli Ø (2010) Forebrain cell proliferation, behavior, and physiology of zebrafish, Danio rerio, kept in enriched or barren environments. Physiol Behav 101:32-39. https://doi.org/10.1016/j. physbeh.2010.04.003

Yopak KE, Pakan JMP, Wylie D (2017) The cerebellum of nonmammalian vertebrates. In: Striedter G (ed) Evolution of nervous systems, vol 1, Second edn. Academic Press, Oxford, pp 373-385

Publisher's note Springer Nature remains neutral with regard to jurisdictional claims in published maps and institutional affiliations. 